\title{
Covid-19 and the next outbreak: decreasing frailty by using mild stress?
}

\author{
Eric Le Bourg $(\mathbb{D}$
}

Received: 11 May 2021/Accepted: 1 July 2021 / Published online: 17 July 2021

(C) The Author(s), under exclusive licence to Springer Nature B.V. 2021, corrected publication 2021

\begin{abstract}
The coronavirus disease 2019 (Covid-19) has resulted in many deaths, particularly of very old or obese people. These people are at risk to die in the event of an outbreak, like under one-year old babies were at risk to die one century ago from various diseases. It is argued that mild stress could help people to resist new outbreaks. The people who are obese because of bad feeding habits (snacking, junk food, overfeeding) and inactivity should adopt more healthy behaviours. Because an inactive way of life at old age can increase frailty, physical and mental activities should be kept at the highest possible level in elderly people, particularly if they live in retirement homes. In the event of an outbreak, management staff of these homes should not confine residents in their room for weeks or months, as it can increase inactivity, undernutrition, sarcopenia, and depressive symptoms. People with or without co-morbidities should be active and one could wonder whether other mild stresses such as sauna bathing could help to better resist infection.
\end{abstract}

\footnotetext{
This article is dedicated to the memory of Alexander Vaiserman, an eminent Soviet and Ukrainian biogerontologist, who died in May 2021.
}

\section{E. Le Bourg $(\square)$}

Centre de Recherches sur la Cognition Animale (CRCA), Centre de Biologie Intégrative (CBI Toulouse), Université de Toulouse, CNRS, UPS, Toulouse, France

e-mail: eric.le-bourg@univ-tlse3.fr
Keywords Covid-19 - Mild stress - Future outbreaks $\cdot$ Elderly people $\cdot$ Obesity $\cdot$ Physical activity $\cdot$ Sauna bathing

\section{Introduction}

It is now well accepted that low doses of many stresses-mild stress-do not provoke severe damages but induce adaptive responses improving the ability to resist severe stress, a phenomenon called hormesis (Mattson and Calabrese 2010). Mild stress can increase resistance to severe stress throughout the lifespan in Drosophila melanogaster flies (Le Bourg 2016) and it can also increase lifespan in animal models (review in Le Bourg 2009). Beyond animal models, mild stress may have positive effects in human beings (reviews in Le Bourg and Rattan 2008; Rattan and Le Bourg 2014; Rattan and Kyriazis 2019) and there are debates on the best way to implement the use of mild stress in prevention of disease and in therapy (reviews in Rattan and Kyriazis 2019).

Looking at it the other way round, one could say that the absence of mild stress could have deleterious consequences for health and eventually lifespan. Let us consider food and activity. Regarding food, it could be said that a short fasting is a mild stress inducing protective responses of the organism (review in Mattson et al. 2014) and that such responses have 
been of help in the past, for instance to resist starvation episodes and even famine (e.g. Prentice 2005). Nowadays, hunger is no longer a problem in many countries, except in some cases, up to the point that some people have replaced balanced meals at regular intervals by excessive calories intake, snacking along the day, and junk food. This behaviour can induce obesity that can decrease lifespan, even if being slightly overweight does not (Flegal et al. 2013). Therefore, some people have replaced the mild stress of waiting for the next meal by storing all along the day metabolic reserves that may be of no use in modern life because of a decreased level of physical activity. Physical activity can be considered as a mild stress inducing protective responses of the organism (Radak and Taylor 2019) but, in modern life, a high level of activity has often been replaced by sedentariness (e.g. Walker et al. 2003) with deleterious consequences for health (e.g. Löllgen et al. 2009).

Before the Covid-19 outbreak, obesity and sedentariness were considered as issues associated with cardio-vascular pathologies and thus eventually a shorter lifespan (Flegal et al. 2013; Franco et al. 2013; Manini et al. 2006 but see also Dalene et al. 2021). Most people can nevertheless reach a very old age, thanks for instance to progress in the fight against cardio-vascular diseases (review in Grigoriev et al. 2014), but the price to pay is increased frailty (Fulop et al. 2010) at this old age and a higher risk of dying from events that are not a threat to most of younger people, such as influenza or heatwave (e.g. Jougla and Hemon 2005).

One century ago, frail people were the babies, up to one-third of them dying before one year of age in wealthy countries (e.g. Mercier and Boone 2002) but, today, Covid-19 targets frail aged people, which is not surprising, and obese people (Kaeuffer et al. 2020), in addition to the other risks linked to obesity (Flegal et al. 2013). In such conditions, one could plea for implementing mild stress as a counter-measure of future outbreaks, because it can help to resist severe stress.

\section{Mild stress as a means to fight future outbreaks}

Implementing a mild stress strategy is easy to do but requires the full cooperation of people. Because the Covid-19 kills obese people, one can hope they will probably modify their habits to increase the chance to survive a new outbreak targeting them. In such conditions, public health messages stating that a mild stress (higher activity level and decreased food intake without snacking) is useful to survive a severe stress could help those who are obese and sedentary because of bad feeding and inactivity habits. While it is not clear whether decreased or increased meal frequency can help to fight obesity, it seems better to have a breakfast and a light dinner than to skip breakfast and having a high-calorie dinner (Paoli et al. 2019), but there is no debate on the necessity to avoid overfeeding. Physical activity can reduce cardio-metabolic risk and increase physical fitness of obese people, even if the change in body weight is moderate (Oppert et al. 2021). Therefore, obese people should be encouraged to rely on mild stress by increasing their activity level, not only to enjoy a better health, but also to decrease their risk if being subjected to an infection targeting obese people, as it is the case with the Covid-19.

Beyond obese people, decreasing the activity level of elderly people during lockdowns was probably a bad idea. For instance in France, elderly people living in retirement homes were confined in their bedrooms without requesting their consent (Ladiesse et al. 2020). Confining to bedrooms has made them inactive for months, as being not allowed to have a walk in the garden of the retirement home, and this increased the risk of sarcopenia, a well-known threat at old age (review in Kirk et al. 2020). It was reasoned that elderly people would escape the virus but, because the residents were confined into their bedroom, the risk of contamination by a staff member was much higher than in larger areas with a better air circulation, such as lounges or outside. Residents were now eating meal trays in their bedrooms, without any talk with other residents, which could increase depressive symptoms and was opening the way to a lower food intake and a higher risk of under-nutrition, a well-known threat in elderly people (Kagansky et al. 2005, review in Kalan et al. 2020). The risk for depressive symptoms, that is high in elderly people (review in Dudek et al. 2020), increased, as residents could also not meet their family and friends for months. Finally, the whole picture made that this could increase the risk of death by failure to thrive (Egbert 1996). Preventing undernutrition, sarcopenia, and social isolation can help elderly people to resist infection, even if it could be easier to stay in a armchair all along the day rather than 
having daily walks, social contacts that are sometimes stressful, and cognitive tasks such as crosswords. These activities require physical, psychological or mental efforts which can all be considered as mild stresses. One thus should avoid restricting the daily activities of elderly people but rather encourage them to be active, even if there is an outbreak, and especially if there is an outbreak.

Otherwise, it could be wondered whether mild stress could allow to resist infection, not only in obese and elderly people, as it has been explicitly stated by Kunutsor and Laukkanen (2021). These authors showed that higher frequency of sauna bathing and maximal oxygen uptake, "an index of habitual physical activity", had a synergistic positive effect on the risk of pneumonia in a 26 years study of Finnish men. Regarding Covid-19, they concluded that "randomized clinical trials are needed to confirm the robust effectiveness of the combination of physical activity and passive heat therapy in altering infection risk or prognosis". A first step could be to know whether Finnish people practicing sauna bathing were less or more at risk than other ones to be severely impacted by Covid-19, but it seems this information is currently lacking. A higher maximal exercise capacity (cardiorespiratory fitness), measured in patients for various reasons (e.g. heart rate evaluation) up to four years before being SARS-CoV-2-positive, seems to be linked with a lower Covid-19 hospitalisation risk, and this relationship was observed no matter the gender of subjects, their age (lower or higher than 65 years), and obesity status (Brawner et al. 2021, see discussion in Kerrigan et al. 2021 and Lavie et al. 2021). Similarly, people with a better cardiorespiratory fitness had a lower risk of dying from Covid-19 (Christensen et al. 2021). These results have been observed in patients with pathologies and do not show that physical activity could be protective in other people: it has been reported that people with better estimated cardiorespiratory fitness had a lower hospitalisation risk, the results being however just significant $(p=0.04$, Brandenburg et al. 2021). These results could support the hypothesis that, by itself, a regular physical activity, and thus a mild stress, could help resist the virus (see de Larochelambert et al. 2020 for comparisons among countries of sedentary behaviour and Covid-19 mortality).

\section{Conclusions}

The Covid-19 outbreak will stop, one day, but other outbreaks could happen in the future and it is necessary to implement new protective strategies, in the hope to minimise the death toll. Using mild stress appears to be sound, because it induces adaptive responses improving the ability to resist severe stress. For obese people, decreasing the food intake and having meals at regular intervals, which implies a short fasting between them, can be an effort and thus a mild stress. For sedentary ones, increasing physical activity is the right strategy, in addition to the other positive effects of activity on health and lifespan (review in Le Bourg 2009). For elderly people, maintaining and increasing daily activities, and particularly physical activity (Weeks and Beck 2020), social contacts and preventing undernutrition seems appropriate. For people with or without co-morbidities, relying on mild stress by increasing physical activity level, and maybe sauna bathing, could be an appropriate strategy in everyday life. All these behaviours are not always spontaneous ones, and thus require an effort, which is a mild stress. However, it is maybe a price to pay for a better life and higher chance to survive in the event of infection.

Modern life is concomitant with a reduced level of stress for many people: no need to wait for the next meal as one can snack at any time, no need to exercise as the car can be used to go to the next street corner, no need to exercise the brain as watching a reality-TV show is easier than reading a book, making crosswords or sudoku. The net result is that many rather young obese people were frailer than they believed and unable to resist Covid-19: they died. Decreasing the stress level in everyday life decreased the ability to resist severe stress and it is thus needed to accept to increase this level: indeed, for many people, whatever their age, the Covid-19 has shown that it can be a matter of life or death.

For elderly people, the take-home message is that they should not consider that retirement is the time of full rest and that a low level of activity is "normal" at this age, if not desirable, to the point that Belgian retirement homes are called "Maison de repos" (Rest home). Older people should keep active, physically and cognitively, as it is probably the best means to remain healthy (e.g. Weeks and Beck 2020), and thus probably to better resist diseases. 


\section{References}

Brandenburg JP, Lesser IA, Thomson CJ, Giles LV (2021) Does higher self-reported cardiorespiratory fitness reduce the odds of hospitalization from COVID-19? J Phys Act Health 18:782-788

Brawner CA, Ehrman JK, Bole S, Kerrigan DJ, Parikh SS, Lewis BK, Gindi RM, Keteyian C, Abdul-Nour K, Keteyian SJ (2021) Inverse relationship of maximal exercise capacity to hospitalization secondary to coronavirus disease 2019. Mayo Clinic Proc 96:32-39

Christensen RAG, Arneja J, St. Cyr K, Sturrock SL, Brooks JD (2021) The association of estimated cardiorespiratory fitness with COVID-19 incidence and mortality: a cohort study. PLoS One 16:e0250508

Dalene KE, Tarp J, Selmer RM, Ariansen IKH, Nystad W, Coenen P, Anderssen SA, Steene-Johannessen J, Ekelund U (2021) Occupational physical activity and longevity in working men and women in Norway: a prospective cohort study. Lancet Public Health 6:e386-e395

De Larochelambert Q, Marc A, Antero J, Le Bourg E, Toussaint JF (2020) Covid-19 mortality: a matter of vulnerability among nations facing limited margins of adaptation. Front Public Health 8:604339

Dudek D, Rachel W, Cyranka C (2020) Depression in older people. In: Rattan SIS, Barbagallo M, Le Bourg E (eds) Encyclopedia of biomedical gerontology. Elsevier, Netherlands

Egbert AM (1996) The dwindles: failure to thrive in older patients. Nutr Rev 54:S25-S30

Flegal KM, Kit BK, Orpana H, Graubard BI (2013) Association of all-cause mortality with overweight and obesity using standard body mass index categories: a systematic review and meta-analysis. J Amer Med Assoc 309:71-82

Franco M, Bilal U, Orduñez P, Benet M, Morejón A, Caballero B, Kennelly JF, Cooper RS (2013) Population-wide weight loss and regain in relation to diabetes burden and cardiovascular mortality in Cuba 1980-2010: repeated cross sectional surveys and ecological comparison of secular trends. Brit Med J 346:F1515

Fulop T, Larbi A, Witkowski JM, McElhaney J, Loeb M, Mitnitski A, Pawelec G (2010) Aging, frailty and age-related diseases. Biogerontology 11:547-563

Grigoriev P, Meslé F, Shkolnikov VM, Andreev E, Fihel A, Pechholdova M, Vallin J (2014) The recent mortality decline in Russia: beginning of the cardiovascular revolution? Pop Dev Rev 40:107-129

Jougla E, Hemon D (2005) Consequences of the 2003 summer heat wave on mortality levels in France. In: Carey JR, Robine JM, Michel JP, Christen Y (eds) Longevity and frailty. Springer, Berlin, pp 125-138

Kaeuffer C, Le Hyaric C, Fabacher T, Mootien J, Dervieux B, Ruch Y, Hugerot A, Zhu YJ, Pointurier V, Clere-Jehl R, Greigert V, Kassegne L, Lefebvre N, Gallais F, Covid Alsace Study Group, Meyer N, Hansmann Y, Hinschberger O, Danion F (2020) Clinical characteristics and risk factors associated with severe COVID-19: prospective analysis of 1045 hospitalised cases in North-Eastern France, March 2020. Eurosurveill 25(48):2000895
Kagansky N, Berner Y, Koren-Morag N, Perelman L, Knobler H, Levy S (2005) Poor nutritional habits are predictors of poor outcome in very old hospitalized patients. Am J Clin Nutr 82:784-791

Kalan U, Arik F, Soysal P (2020) Malnutrition in older people. In: Rattan SIS, Barbagallo M, Le Bourg E (eds) Encyclopedia of biomedical gerontology. Elsevier, Netherlands

Kerrigan DJ, Brawner CA, Ehrman JK, Keteyian S (2021) Cardiorespiratory fitness attenuates the impact of risk factors associated with covid-19 hospitalization. Mayo Clinic Proc 96:822-823

Kirk B, Phu S, Debruin DA, Hayes A, Duque G (2020) Aging muscle and sarcopenia. In: Rattan SIS, Barbagallo M, Le Bourg E (eds) Encyclopedia of biomedical gerontology. Elsevier, Netherlands

Kunutsor SK, Laukkanen JA (2021) High fitness levels, frequent sauna bathing and risk of pneumonia in a cohort study: are there potential implications for COVID-19? Eur J Clin Invest 51:e13490

Ladiesse M, Léonard T, Birmelé B (2020) Les libertés en EHPAD, à l'épreuve du confinement (Freedom in retirement home, facing confinement). Ethique Santé 17:147-154

Lavie CJ, Sanchis-Gomar F, Arena R (2021) In reply-cardio respiratory fitness attenuates the impact of risk factors associated with covid-19 hospitalization. Mayo Clinic Proc 96:823-824

Le Bourg E (2009) Hormesis, aging, and longevity. Biochim Biophys Acta 1790:1030-1039

Le Bourg E (2016) Life-time protection against severe heat stress by exposing young Drosophila melanogaster flies to a mild cold stress. Biogerontology 17:409-415

Le Bourg E, Rattan SIS (eds) (2008) Mild stress and healthy aging. Applying hormesis in aging research and interventions. Springer, Berlin

Löllgen H, Böckenhoff A, Knapp G (2009) Physical activity and all-cause mortality: an updated meta-analysis with different intensity categories. Int J Sports Med 30:213-224

Manini TM, Everhart JE, Patel KV, Schoeller DA, Colbert LH, Visser M, Tylavsky F, Bauer DC, Goodpaster BH, Harris TB (2006) Daily activity energy expenditure and mortality among older adults. J Am Med Assoc 296:171-179

Mattson MP, Calabrese EJ (eds) (2010) Hormesis A revolution in biology, toxicology and medicine. Springer, Heidelberg

Mattson MP, Allison DB, Fontana L, Harvie M, Longo VD, Malaisse WJ, Mosley M, Notterpek L, Ravussin E, Scheer FA, Seyfried TN, Varady KA, Panda S (2014) Meal frequency and timing in health and disease. Proc Natl Acad Sci USA 111:16647-16653

Mercier ME, Boone CG (2002) Infant mortality in Ottawa, Canada, 1901: assessing cultural, economic and environmental factors. J Hist Geogr 28:486-507

Oppert JM, Bellicha A, van Baak MA, Battista F, Beaulieu K, Blundell JE, Carraça EV, Encantado J, Ermolao A, Pramono A, Farpour-Lambert N, Woodward E, Dicker D, Busetto L (2021) Exercise training in the management of overweight and obesity in adults: synthesis of the evidence and recommendations from the European Association for the Study of Obesity Physical Activity Working Group. Obes Rev 4:e13273 
Paoli A, Tinsley G, Bianco A, Moro T (2019) The influence of meal frequency and timing on health in humans: the role of fasting. Nutrients 11:719

Prentice AM (2005) Starvation in humans: evolutionary background and contemporary implications. Mech Ageing Dev 126:976-981

Radak Z, Taylor AW (2019) Exercise and hormesis. In: Rattan SIS, Kyriazis M (eds) The science of hormesis in health and longevity. Elsevier, London, pp 63-73

Rattan SIS, Kyriazis M (eds) (2019) The science of hormesis in health and longevity. Elsevier, London

Rattan SIS, Le Bourg E (eds) (2014) Hormesis in health and disease. CRC Press, Boca Raton
Walker ARP, Walker BF, Adam F (2003) Nutrition, diet, physical activity, smoking, and longevity: from primitive hunter-gatherer to present passive consumer-how far can we go? Nutrition 19:169-173

Weeks BK, Beck BR (2020) Exercise and physical activity recommendations for optimizing musculoskeletal health in older adults. In: Rattan SIS, Barbagallo M, Le Bourg E (eds) Encyclopedia of biomedical gerontology. Elsevier, Netherlands

Publisher's Note Springer Nature remains neutral with regard to jurisdictional claims in published maps and institutional affiliations. 